\title{
Phthalate Plasticizers in Children's Products and Estimation of Exposure: Importance of Migration Rate
}

\author{
Du Yung Kim ${ }^{1}$, Sa-Ho Chun ${ }^{2}$, Yerin Jung ${ }^{1}$, Dana Fahad Mohamed Salman Mohamed ${ }^{1}$ (D), \\ Hae-Soo Kim ${ }^{2}$, Da-Young Kang ${ }^{2}$, Jeong-Won An ${ }^{2}$, Seong-Yeol Park ${ }^{2}$, Hyun-Wook Kwon ${ }^{2}$ and \\ Jung-Hwan Kwon $1, *$ (D) \\ 1 Division of Environmental Science and Ecological Engineering, Korea University, 145 Anam-ro, \\ Seongbuk-gu, Seoul 02841, Korea; duyungkim@korea.ac.kr (D.Y.K.); qtwree@korea.ac.kr (Y.J.); \\ danasalman@korea.ac.kr (D.F.M.S.M.) \\ 2 FITI Testing \& Research Institute, 21 Yangcheong 3-gil, Ochang-eup, Cheongwon-gun, Cheongju-si, \\ Chungcheongbuk-do 28115, Korea; shchun@fiti.re.kr (S.-H.C.); haesoo@fiti.re.kr (H.-S.K.); \\ dykang@fiti.re.kr (D.-Y.K.); jwan@fiti.re.kr (J.-W.A.); Psy065@fiti.re.kr (S.-Y.P.); khw@fiti.re.kr (H.-W.K.) \\ * Correspondence: junghwankwon@korea.ac.kr; Tel.: +82-2-3290-3041
}

Received: 16 October 2020; Accepted: 17 November 2020; Published: 19 November 2020

\begin{abstract}
Plasticizers are added to diverse consumer products including children's products. Owing to their potential for endocrine disruption, the use of phthalate plasticizers is restricted in many children's products. In this study, exposure to five phthalate esters (dibutylphthalate, di(2-ethylhexyl) phthalate (DEHP), diethyl phthalate, di-isobutyl phthalate, and diisononyl phthalate (DINP)) and an alternative (di-ethylhexyl adipate) was assessed by the use of children's products based on chemical analysis of 3345 products purchased during 2017 and 2019 in Korea. Plasticizers were found above the detection limits in 387 products, and DEHP and DINP were the two most predominantly detected plasticizers. Deterministic and probabilistic estimation of the margin of exposure at a screening level revealed that the use of children's products might be an important risk factor. However, it is also highly likely that the exposure could be overestimated, because the migration rate was estimated based solely on the content of plasticizers in children's products. Chemical migration is a key process determining the absorption of plasticizers from products; thus, further refinements in experimental determination or model estimation of the migration rate are required.
\end{abstract}

Keywords: children; phthalate esters; plasticizers; consumer products; exposure assessment; migration

\section{Introduction}

Phthalate plasticizers are widely used to enhance the elasticity and durability of numerous plastic products $[1,2]$. With increasing volumes of plastic products being produced, the amount of phthalate plasticizers being used is increasing as well [3]. Many phthalate plasticizers are suspected to be potential endocrine-disrupting chemicals because of their adverse effects on reproductive development $[4,5]$. Thus, many countries have regulations concerning the use of phthalate plasticizers in consumer products [6-11]. Exposure assessment based on the concentration of phthalate plasticizers in children's products is crucial, because children are more susceptible to those plasticizers.

In recent decades, phthalate plasticizers in children's products such as toys, teethers, and backpacks were analyzed in numerous studies [12-18]. They were found in various polymeric parts of a product, especially polyvinyl chloride (PVC). Of the analyzed products, some had two or more phthalate plasticizers, but most products had one phthalate plasticizer. In the early 2000s, diisononyl phthalate (DINP) was the predominant phthalate plasticizer in PVC toys, of which concentration was up to $44 \%$, and di(2-ethylhexyl)phthalate (DEHP) was the second-most dominant [12,13]. From the late 
2000s, DEHP became the most used phthalate ester, accounting for more than $50 \%$ of total phthalate production [3,19]. In addition to DINP and DEHP, other common phthalate plasticizers have been used in many plastic products. Because of their abundance in children's products, quantitative assessment of exposure to phthalate plasticizers should be prioritized.

Exposure models, such as the consumer exposure model (CEM) from the U.S. Environmental Protection Agency (EPA) and ConsExpo from the National Institute for Public Health and the Environment of the Netherlands (RIVM), were developed to estimate the human exposure from diverse consumer products through various exposure pathways. Such user-friendly models include various exposure scenarios consisting of product types, exposure pathways, and exposure factors. Many parameters in those estimation models are also provided by default or calculated using basic physicochemical properties such as vapor pressure. Though estimation models are widely used because of their convenience, inherent uncertainties are inevitable in exposure estimation due to the default exposure factors of the model. In CEM, for example, the estimated exposure through ingesting product debris has been strongly affected by the migration rate in the digestive system. Users can choose one among five migration rate values as input data, and this simple choice might lead to an overestimation of exposure. Thus, identification of critical input parameters causing large uncertainties in the estimation and refining the range of uncertain parameters should be very important toward more reliable estimation.

In this study, the concentrations of five phthalate esters (i.e., dibutyl phthalate (DBP), DEHP, diethyl phthalate (DEP), di-isobutyl phthalate (DIBP), and DINP) and an alternative, di-ethylhexyl adipate (DEHA), were analyzed in 3345 children's products purchased from 2017 to 2019 in Korea to understand the baseline level of those plasticizers in children's products. Exposure to phthalates and DEHA from children's products through ingestion and dermal absorption was estimated with measured concentrations in products. Exposure assessment was conducted relying on the exposure algorithms adopted in CEM by both deterministic calculation and probabilistic estimation using Monte Carlo simulation. Finally, the margin of exposure (MOE) of each chemical was calculated and critical parameters determining estimation uncertainty were identified.

\section{Materials and Methods}

\subsection{Purchase of Samples}

Different children's products $(\mathrm{n}=3345)$ were purchased from on- and off-line stores between 2017 and 2019. They were categorized into six groups: children's accessories, mats, shoes, stationeries, toilets, and toys. Detailed items in those six product categories are summarized in Table 1. Only the part made of plastic material was separated from a product and subjected to chemical analysis.

\subsection{Chemicals}

For analytical standard, DBP, DEHP, and DINP were purchased as a mixture from AccuStandard (PLAS-CPSC mixture, $500 \mu \mathrm{g} \mathrm{mL}{ }^{-1}$ each, New Haven, CT, USA). Individual standards of DEP, DEHA, and DIBP were purchased from AccuStandard (ALR-110S, $100 \mu \mathrm{g} / \mathrm{mL}$ and P-233S, $1000 \mu \mathrm{g} / \mathrm{mL}$ ) and Sigma-Aldrich (152641, 99.7\%, St. Louis, MO, USA), respectively. All organic solvents (methanol, tetrahydrofuran, acrylonitrile, etc.) used in sample preparation were of analytical grade. 
Table 1. Classification of purchased products and number of chemicals detected.

\begin{tabular}{|c|c|c|c|c|}
\hline \multirow[t]{2}{*}{ Category } & \multirow[t]{2}{*}{ Number of Products } & \multirow{2}{*}{$\begin{array}{l}\text { Sub-Category of Products } \\
\text { (Total Number of Samples) }\end{array}$} & \multicolumn{2}{|c|}{$\begin{array}{c}\text { Number of Products in Which Chemicals Were } \\
\text { Above Detection Limits }\end{array}$} \\
\hline & & & Chemical & Number \\
\hline \multirow{4}{*}{ Accessories } & \multirow{4}{*}{605} & \multirow{4}{*}{$\begin{array}{l}\text { Clothes (116), jewelry (240), mobile accessories (85), } \\
\text { household stuffs (82), DIY tools (82) }\end{array}$} & DBP & 6 \\
\hline & & & DEHA & 15 \\
\hline & & & DEHP & 51 \\
\hline & & & DINP & 29 \\
\hline \multirow{3}{*}{ Mat } & \multirow{3}{*}{110} & \multirow{3}{*}{ Non-slip mat (11), play mat (99) } & DBP & 1 \\
\hline & & & DEHP & 6 \\
\hline & & & DINP & 1 \\
\hline \multirow{3}{*}{ Shoes } & \multirow{3}{*}{176} & \multirow{3}{*}{$\begin{array}{l}\text { Roller shoes (25), sandals (36), summer shoes (59), } \\
\text { indoor shoes ( } 42) \text {, shower sandals (14) }\end{array}$} & DBP & 36 \\
\hline & & & DEHP & 30 \\
\hline & & & DINP & 29 \\
\hline \multirow{5}{*}{ Stationery } & \multirow{5}{*}{785} & \multirow{5}{*}{$\begin{array}{l}\text { Beauty and personal care (10), kitchen stuffs (41), office products (552), } \\
\text { painting and drawing supplies (82), tools and furniture (100) }\end{array}$} & DBP & 11 \\
\hline & & & DEHA & 6 \\
\hline & & & DEHP & 126 \\
\hline & & & DIBP & 1 \\
\hline & & & DINP & 54 \\
\hline \multirow{2}{*}{ Toilet } & \multirow{2}{*}{38} & \multirow{2}{*}{ Potty toilet (38) } & DEHP & 5 \\
\hline & & & DINP & 9 \\
\hline \multirow{6}{*}{ Toy } & \multirow{6}{*}{1631} & \multirow{6}{*}{$\begin{array}{l}\text { Gift and party goods (168), play figures (780), shape and size of certain } \\
\text { toys (75), arts and crafts (537), preschool Games (11), aquatic toys (37), } \\
\text { other infant toys (23) }\end{array}$} & DBP & 12 \\
\hline & & & DEHA & 9 \\
\hline & & & DEHP & 46 \\
\hline & & & DEP & 10 \\
\hline & & & DIBP & 13 \\
\hline & & & DINP & 19 \\
\hline Sum & 3345 & - & & \\
\hline
\end{tabular}

DBP (dibutyl phthalate), DEHA (di(e-ethylhexyl)adipate), DEHP (di(2-ethylhexyl)phthalate), DEP (diethyl phthalate), DIBP (di-isobutyl phthalate), DINP (diisononyl phthalate). 


\subsection{Sample Preparation and Instrumentation}

\subsubsection{Sample Preparation}

For sample extraction, the proposed procedure of CPSC-CH-C1001-09.4 [20] and Standard Method for Environmental Hazard [21] were applied. Each plastic part was separated from the product and cut into small pieces less than $2 \mathrm{~mm}$ or milled into a powder. For extracting plasticizers, approximately $0.3-1.0 \mathrm{~g}$ of the weighed sample was submerged in 10-15 $\mathrm{mL}$ of tetrahydrofuran in a glass vial. To allow dissolution, the vial was sonicated for $30 \mathrm{~min}$, followed by additional $2 \mathrm{~h}$ sonication in case that the sample was not completely dissolved. Then, $10-15 \mathrm{~mL}$ of acrylonitrile or methanol was added to precipitate the polymer. After vigorous shaking, suspended particles that formed were allowed to settle for $5 \mathrm{~min}$. The supernatant was then filtered through a $0.45 \mu \mathrm{m}$ polytetrafluoroethylene filter and analyzed using gas chromatography mass spectrometry (GC-MS). Triplicate analyses were conducted for samples in which phthalate(s) were determined above the quantification limits in the first analysis.

\subsubsection{Chemical Analysis}

The analysis of the extracted solution was conducted by GC-MS (Shimadzu GCMS-QP2020, Kyoto, Japan). The temperature of the injector was $280^{\circ} \mathrm{C}$ and injection volume was $1 \mu \mathrm{L}$. Helium was used as carrier gas at $1.0 \mathrm{~mL} / \mathrm{min}$. Fused silica capillary column (DB-5ms, $30 \mathrm{~m} \times 0.25 \mathrm{~mm} \times 0.25 \mu \mathrm{m}$ ) was used for the separation. The oven temperature was programmed from $80^{\circ} \mathrm{C}$ (held for $0.5 \mathrm{~min}$ ), raised to $280{ }^{\circ} \mathrm{C}$ at $10{ }^{\circ} \mathrm{C} \mathrm{min}-1$, and subsequently, raised to $320^{\circ} \mathrm{C}$ at $25^{\circ} \mathrm{C} \mathrm{min}-1$ held for $7 \mathrm{~min}$. The temperature of the ion source was $230^{\circ} \mathrm{C}$ for detector. NIST 08 MS Library and MS Search Program v.2.0 (The NIST Mass Spectrometry Data Center, 2008) was used for phthalate identification, and the mass spectrum scan range for qualitative analysis was $m / z 50-500$. Mass-to-charge ratios $(\mathrm{m} / \mathrm{z}) 149,205$, 223 (for DBP, DIBP), 149, 167, 279 (for DEHP), 149, 293, 307 (for DINP), 65, 149, 177 (for DEP), 129, 147 (for DEHA) were monitored for quantitative analysis.

Limit of quantitation (LOQ) was calculated as $30.6 \mathrm{mg} \mathrm{kg}^{-1}$ (DBP), $33.1 \mathrm{mg} \mathrm{kg}^{-1}$ (DIBP), $32.5 \mathrm{mg}$ $\mathrm{kg}^{-1}$ (DEHP), $35.6 \mathrm{mg} \mathrm{kg}^{-1}$ (DINP), $44.0 \mathrm{mg} \mathrm{kg}^{-1}$ (DEP), and $41.0 \mathrm{mg} \mathrm{kg}^{-1}$ (DEHA), respectively. However, the LOQ was calculated at the level of about $40 \mathrm{mg} \mathrm{kg}^{-1}$ as described above, but in consideration of the safety factor, only children's products detected over $100 \mathrm{mg} \mathrm{kg}^{-1}$ were used for exposure assessment.

\subsection{Exposure Estimation}

\subsubsection{Exposure Algorithms through Ingestion and Dermal Absorption}

Ingestion of product debris or indoor dust, dermal absorption, and inhalation are three major routes of human exposure to phthalate esters and DEHA. Exposure pathways through ingesting indoor dust and inhalation of gaseous chemicals were excluded, because there might be other important sources determining their concentration in indoor air and dust [22]. The exposure through the ingestion of product debris and dermal absorption was estimated with algorithms provided by CEM [23]. Daily dose by ingestion (Daily dose ingestion $_{\text {) }}$ and dermal absorption (Daily dose dermal $_{\text {in }}$ ) was expressed as Equations (1) and (2), and parameters used in those equations were estimated using Equations (3)-(7).

$$
\begin{aligned}
& \text { Daily dose } e_{\text {ingestion }}=\frac{M R \times C A \times D_{\text {mouthing }} \times E D}{B W \times A T} \\
& \text { Daily dose }_{\text {dermal }}=\frac{C_{a r t} \times \frac{S A}{B W} \times l \times F A \times E D}{A T} \\
& l=\sqrt{2 \times D \times D u r / 60}
\end{aligned}
$$




$$
\begin{gathered}
F A=\frac{3+\chi\left[1-\exp \left(-a \frac{D u r}{\frac{D u r}{t_{\text {lag }}}}\right)\right]}{3(1+\chi)} \\
\chi=\frac{h \times p_{\text {vap }} \times M W}{K_{p} \times S_{w} \times R \times T} \\
t_{\text {lag }}=\frac{h_{s c}}{6 \times 10^{-2.8-0.0056 M W}} \\
K_{p}=\frac{1}{\left(\frac{1}{K_{\text {lip }}+K_{\text {pol }}}\right)+\left(\frac{1}{K_{a q}}\right)}
\end{gathered}
$$

Definitions of all parameters in the exposure estimation with their units are listed in Table 2.

Table 2. Input parameters for the estimation of exposure.

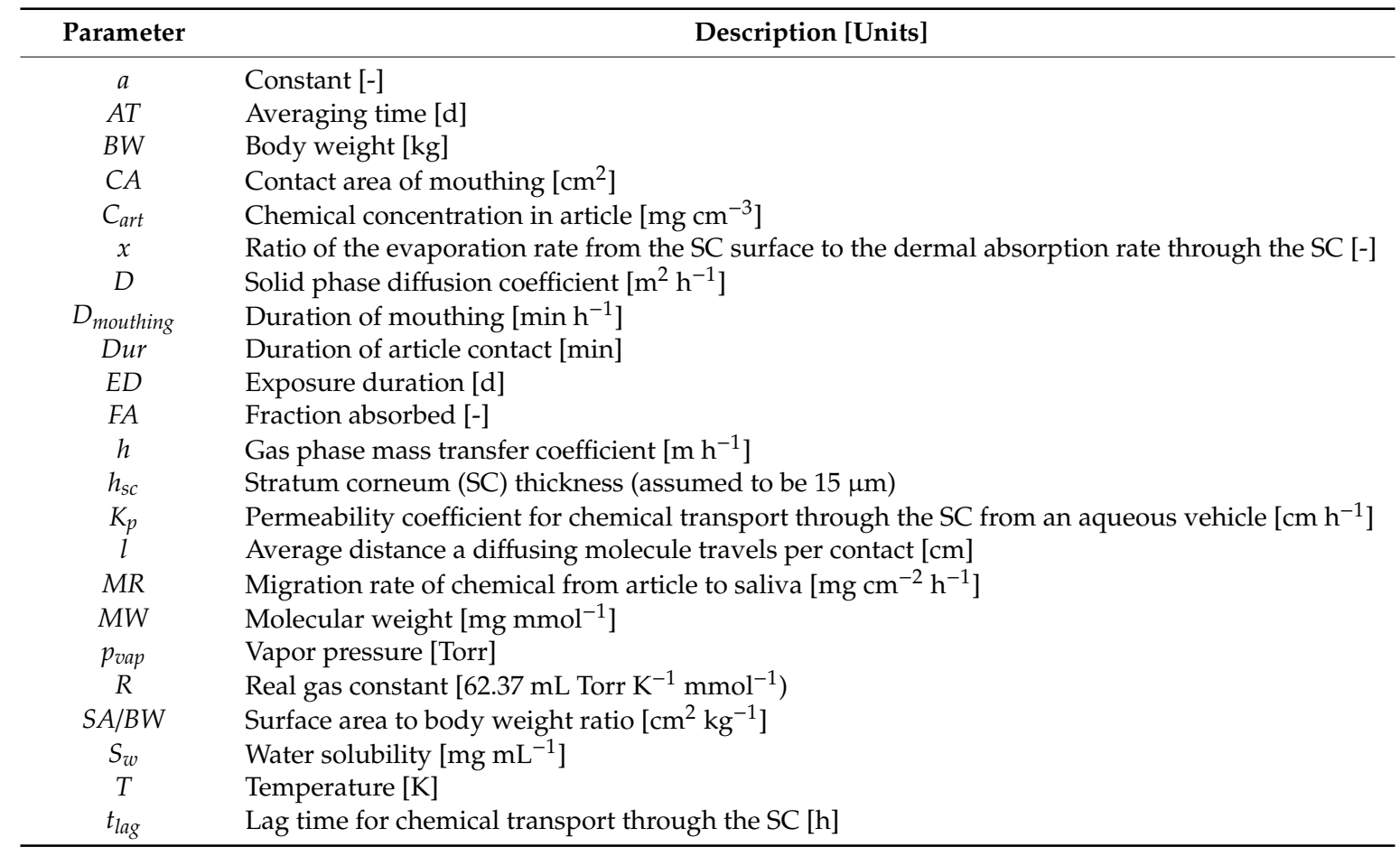

\subsubsection{Deterministic Estimation}

The minimum and the maximum daily dose of each plasticizer in a product category were calculated using Equations (1) and (2). For ingestion exposure, the migration rate of each chemical is decided by concentration in a product. The migration rate was assigned to be $10 \mathrm{mg} \mathrm{cm}^{-2} \mathrm{~h}^{-1}$ when the content of the chemical is over $1 \%(w / w)$, and $0.1 \mathrm{mg} \mathrm{cm}^{-2} \mathrm{~h}^{-1}$ when the content is less than $1 \%$ $(w / w)$. In the case of dermal absorption, the highest and the lowest concentrations of each chemical were used to calculate the exposure range. The values of other exposure parameters in Equation (2) were defaults or calculated from input parameters based on CEM.

\subsubsection{Probabilistic Estimation}

A probabilistic approach to Equations (1) and (2) was also considered to estimate exposure to each chemical. Exposure throughout all product categories was summed by using Monte Carlo simulation to estimate exposure by incorporating uncertainty of the exposure parameters, such as $E D$ [24]. Monte Carlo simulation repeatedly draws random parameter values from the probability density function of each parameter and estimates approximate distributions of the result. Crystal Ball 
software (Oracle, Redwood City, CA, USA) was used for Monte Carlo simulation in Microsoft Excel (Microsoft Corp, Redmond, WA, USA) spreadsheets. After 10,000 iterations, the median and $95 \%$ value of the daily exposure dose were obtained.

Probability density function of $M R$ and $C_{a r t}$ by product categories was estimated using chemical concentrations including not-detected values as half of the detection limits [25]. For estimating the probability density function of parameters, mean and standard deviation values of $C A, E D, S A$, and $B W$ were referred from the Korean children exposure parameter book [26], and the mean and 95 percentile values of $D$ were referred from the CEM guidebook [23]. Different values of $E D$ were chosen according to product categories: daily duration of stay-in-home for accessories; stay-out-of-home for shoes; playing mat and toy; study for stationery; personal sanitation for toilet. Based on the chosen $E D$, children were assumed to use all the product categories. Hands were assumed as the only route of dermal contact. Exposed children were divided into two groups by age (i.e., 0-2 years and 3-12 years) for time-effective simulation and by considering different physiological and behavioral (mouthing) patterns [27]. For other parameters, except $M R, C A, D, E D, C_{a r t}, S A$, and $B W$, the same default values in CEM were used as in Section 2.4.2.

\section{Results}

\subsection{Occurrence of Phthalate Esters and DEHA}

Among the analyzed 3345 products, at least one plasticizer was determined above the detection limit in 387 products, and only one plasticizer was determined in 286 products. DEP was the only chemical used singularly in 10 toys, but DEHP was found in all samples containing more than 1 plasticizer with the exceptions of two products in shoes category in which the combination of DINP and DBP was found. The most frequently detected plasticizer was DEHP in 264 products, followed by DINP $(n=141)$, DBP $(n=66)$, DEHA $(n=30)$, DIBP $(n=14)$, and DEP $(n=10)$. DEHP was found in all product categories. Figure 1 presents the range of plasticizer contents in six product categories in which each plasticizer was detected. In accessories, the highest concentrations of DBP, DEHA, DEHP, and DINP were $0.35,0.59,22.90$, and $15.52 \%(w / w)$, respectively. In mat, the highest concentrations of DBP, DEHP, and DINP were $0.01,20.13$, and $0.06 \%(w / w)$, respectively. In shoes, the highest concentrations of DBP, DEHP, and DINP were 33.12, 38.95, and $14.34 \%(w / w)$, respectively. In stationery, the highest concentrations of DBP, DEHA, DEHP, DIBP, and DINP were 0.16, 0.20, 33.68, 0.01 , and $40.52 \%(w / w)$, respectively. In toilet, the highest concentrations of DEHP and DINP were 8.41, and $4.83 \%(w / w)$, respectively. In toy, the highest concentrations of DBP, DEHA, DEHP, DEP, DIBP, and DINP were $8.03,0.08,28.11,0.92,27.20$, and $4.68 \%(w / w)$, respectively. The highest concentration of plasticizer in analyzed products was $40.52 \%(w / w)$ of DINP in an eraser in the stationery category. The concentrations of DEHP were relatively high in all categories but not always the highest. The high detection frequency and concentration of DEHP might be associated with its good performance as a plasticizer and relatively low price [3,19].

\subsection{Estimated Exposure and Margin of Exposure (MOE)}

The exposure ranges of phthalate plasticizers in children's products were estimated by both deterministic and probabilistic estimation. Table 3 summarizes the values of the reference dose, calculated exposure ranges between the maximum and minimum, and the MOE values by product category. The exposure ranges by ingestion were estimated only for accessories, stationery, and toy categories, because it is unlikely that oral ingestion is significant for other categories. The maximum and minimum exposure limits were estimated between $5.0 \times 10^{-1}$ and $5.0 \times 10^{-3} \mathrm{mg} \mathrm{kg}^{-1} \mathrm{~d}^{-1}$. Two discrete values of the migration rates, 10 and $0.1 \mathrm{mg} \mathrm{cm}^{-2} \mathrm{~h}^{-1}$, were assigned at the concentration of chemical greater than and less than $1 \%(w / w)$. The oral exposure to DEHP and DINP by three categories was $5.0 \times 10^{-1} \mathrm{mg} \mathrm{kg}^{-1} \mathrm{~d}^{-1}$, because the highest concentration of DEHP and DINP exceeded $1 \%$. The exposure to DBP by accessories and stationery was $5.0 \times 10^{-3} \mathrm{mg} \mathrm{kg}^{-1} \mathrm{~d}^{-1}$; in the case of toy, the 
value was $5.0 \times 10^{-1} \mathrm{mg} \mathrm{kg}^{-1} \mathrm{~d}^{-1}$, where the concentrations of two products (dart and doll) were higher than 1\%. DEHA and DEP had only $5.0 \times 10^{-3} \mathrm{mg} \mathrm{kg}^{-1} \mathrm{~d}^{-1}$ in all categories because of their low concentrations. The dermal exposure ranged from $4.9 \times 10^{-7}$ to $1.8 \mathrm{mg} \mathrm{kg}^{-1} \mathrm{~d}^{-1}$ in all categories. The maximum exposure to DEHP via dermal absorption was higher because of its high contents. The MOE values based on the reference doses ranged over seven orders of magnitude, 1.1 to $3.1 \times 10^{7}$. The highest MOEs were observed for DINP, because the dermal absorption is the only exposure pathway in categories of mat, shoes, and toilet.

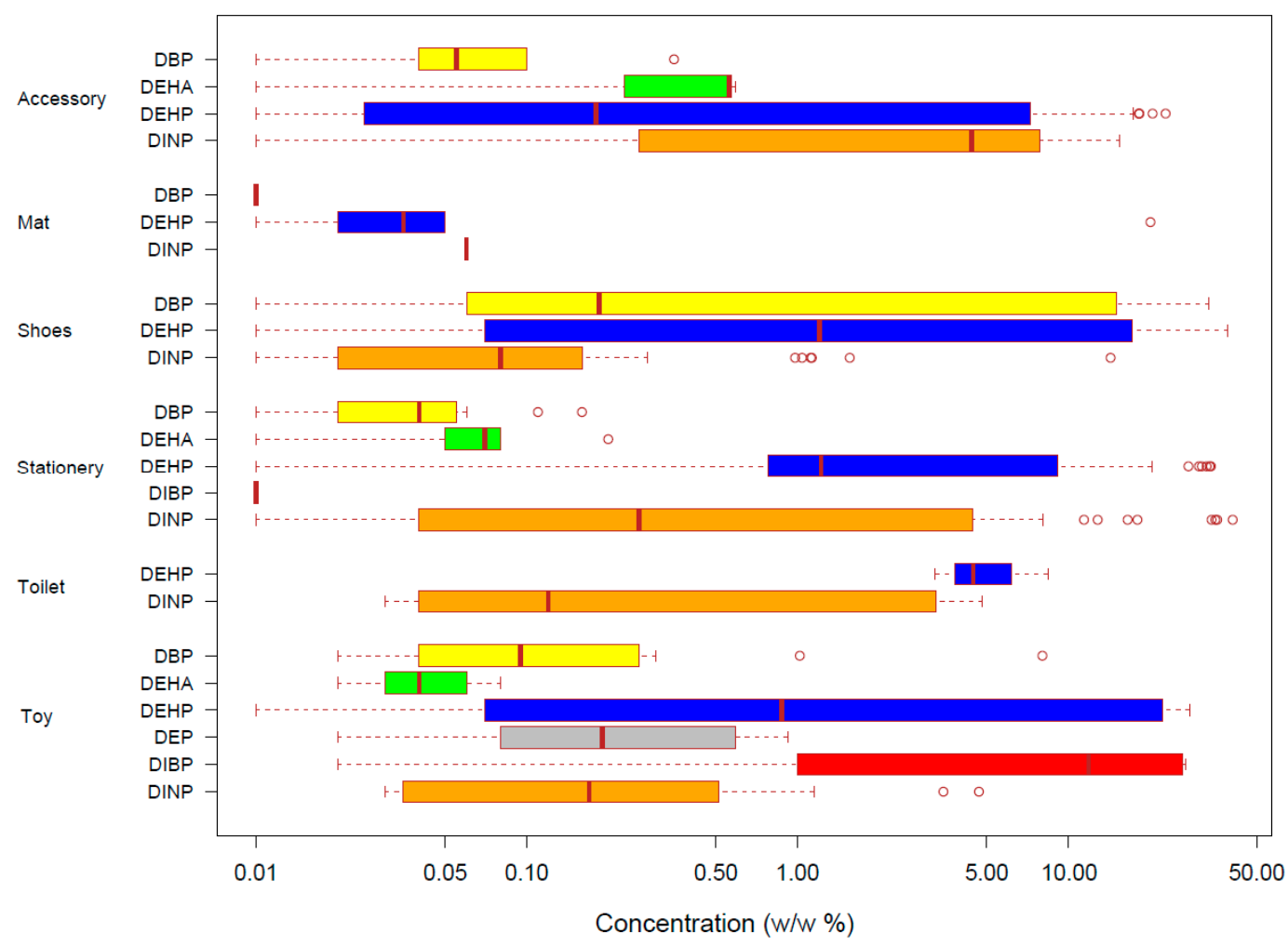

Figure 1. Range of plasticizers' concentration in six categories of children's products in which their concentration was above the detection limits. The box plot describes the minimum, 25 percentile, median, 75 percentile, and the maximum values, with outliers as open circles. Each chemical is expressed in different colors (DBP: yellow, DEHA: green, DEHP: blue, DEP: gray, DIBP: red, and DINP: orange). 
Table 3. Estimated the maximum and minimum exposure ranges and calculated margin of exposure (MOE) from reference dose.

\begin{tabular}{|c|c|c|c|c|c|c|c|c|c|c|}
\hline \multirow{3}{*}{ Category } & \multirow{3}{*}{ Chemical } & \multirow{3}{*}{$\begin{array}{l}\text { Reference Dose } \\
\left(\mathrm{mg} \mathrm{kg}^{-1} \mathrm{~d}^{-1}\right)\end{array}$} & \multicolumn{6}{|c|}{ Exposure Range (mg kg-1 $\mathrm{d}^{-1}$ ) } & \multirow{2}{*}{\multicolumn{2}{|c|}{ MOE }} \\
\hline & & & \multicolumn{2}{|c|}{ Ingestion } & \multicolumn{2}{|c|}{ Dermal } & \multicolumn{2}{|c|}{ Total } & & \\
\hline & & & Max & Min & Max & Min & Max & Min & Max & Min \\
\hline \multirow{4}{*}{ Accessories } & DBP & $2^{1}$ & $5.0 \times 10^{-3}$ & $5.0 \times 10^{-3}$ & $1.9 \times 10^{-2}$ & $5.5 \times 10^{-4}$ & $2.4 \times 10^{-2}$ & $5.5 \times 10^{-3}$ & $8.2 \times 10^{1}$ & $3.6 \times 10^{2}$ \\
\hline & DEHA & $170^{2}$ & $5.0 \times 10^{-3}$ & $5.0 \times 10^{-3}$ & $2.0 \times 10^{-4}$ & $3.5 \times 10^{-6}$ & $5.2 \times 10^{-3}$ & $5.0 \times 10^{-3}$ & $3.3 \times 10^{4}$ & $3.4 \times 10^{4}$ \\
\hline & DEHP & $3^{3}$ & $5.0 \times 10^{-1}$ & $5.0 \times 10^{-3}$ & $2.0 \times 10^{-2}$ & $8.6 \times 10^{-6}$ & $5.1 \times 10^{-1}$ & $5.0 \times 10^{-3}$ & $5.8 \times 10^{0}$ & $6.1 \times 10^{2}$ \\
\hline & DINP & $15^{6}$ & $5.0 \times 10^{-1}$ & $5.0 \times 10^{-3}$ & $7.6 \times 10^{-4}$ & $4.9 \times 10^{-7}$ & $5.0 \times 10^{-1}$ & $5.0 \times 10^{-3}$ & $3.0 \times 10^{1}$ & $3.0 \times 10^{3}$ \\
\hline \multirow{3}{*}{ Mat } & DBP & $2^{1}$ & & & $5.5 \times 10^{-4}$ & $5.5 \times 10^{-4}$ & $5.5 \times 10^{-4}$ & $5.5 \times 10^{-4}$ & $3.6 \times 10^{3}$ & $3.6 \times 10^{3}$ \\
\hline & DEHP & $3^{3}$ & & & $1.7 \times 10^{-2}$ & $8.6 \times 10^{-6}$ & $1.7 \times 10^{-2}$ & $8.6 \times 10^{-6}$ & $1.7 \times 10^{2}$ & $3.5 \times 10^{5}$ \\
\hline & DINP & $15^{6}$ & & & $2.9 \times 10^{-6}$ & $2.9 \times 10^{-6}$ & $2.9 \times 10^{-6}$ & $2.9 \times 10^{-6}$ & $5.1 \times 10^{6}$ & $5.1 \times 10^{6}$ \\
\hline \multirow{3}{*}{ Shoes } & DBP & $2^{1}$ & & & $1.8 \times 10^{0}$ & $5.5 \times 10^{-4}$ & $1.8 \times 10^{0}$ & $5.5 \times 10^{-4}$ & $1.1 \times 10^{0}$ & $3.6 \times 10^{3}$ \\
\hline & DEHP & $3^{3}$ & & & $3.4 \times 10^{-2}$ & $8.6 \times 10^{-6}$ & $3.4 \times 10^{-2}$ & $8.6 \times 10^{-6}$ & $8.9 \times 10^{1}$ & $3.5 \times 10^{5}$ \\
\hline & DINP & $15^{6}$ & & & $7.0 \times 10^{-4}$ & $4.9 \times 10^{-7}$ & $7.0 \times 10^{-4}$ & $4.9 \times 10^{-7}$ & $2.1 \times 10^{4}$ & $3.1 \times 10^{7}$ \\
\hline \multirow{5}{*}{ Stationery } & DBP & $2^{1}$ & $5.0 \times 10^{-3}$ & $5.0 \times 10^{-3}$ & $8.8 \times 10^{-3}$ & $5.5 \times 10^{-4}$ & $1.4 \times 10^{-2}$ & $5.5 \times 10^{-3}$ & $1.5 \times 10^{2}$ & $3.6 \times 10^{2}$ \\
\hline & DEHA & $170^{2}$ & $5.0 \times 10^{-3}$ & $5.0 \times 10^{-3}$ & $6.9 \times 10^{-5}$ & $3.5 \times 10^{-6}$ & $5.0 \times 10^{-3}$ & $5.0 \times 10^{-3}$ & $3.4 \times 10^{4}$ & $3.4 \times 10^{4}$ \\
\hline & DEHP & $3^{3}$ & $5.0 \times 10^{-1}$ & $5.0 \times 10^{-3}$ & $2.9 \times 10^{-2}$ & $8.6 \times 10^{-6}$ & $5.2 \times 10^{-1}$ & $5.0 \times 10^{-3}$ & $5.7 \times 10^{0}$ & $6.1 \times 10^{2}$ \\
\hline & DIBP & $125^{5}$ & $5.0 \times 10^{-3}$ & $5.0 \times 10^{-3}$ & $1.2 \times 10^{-5}$ & $1.2 \times 10^{-5}$ & $5.0 \times 10^{-1}$ & $5.0 \times 10^{-1}$ & $2.5 \times 10^{2}$ & $2.5 \times 10^{2}$ \\
\hline & DINP & $15^{6}$ & $5.0 \times 10^{-1}$ & $5.0 \times 10^{-3}$ & $2.0 \times 10^{-3}$ & $4.9 \times 10^{-7}$ & $5.0 \times 10^{-1}$ & $5.0 \times 10^{-3}$ & $3.0 \times 10^{1}$ & $3.0 \times 10^{3}$ \\
\hline \multirow{2}{*}{ Toilet } & DEHP & $3^{3}$ & & & $7.3 \times 10^{-3}$ & $2.8 \times 10^{-3}$ & $7.3 \times 10^{-3}$ & $2.8 \times 10^{-3}$ & $4.1 \times 10^{2}$ & $1.1 \times 10^{3}$ \\
\hline & DINP & $15^{6}$ & & & $2.4 \times 10^{-4}$ & $1.5 \times 10^{-6}$ & $2.4 \times 10^{-4}$ & $1.5 \times 10^{-6}$ & $6.3 \times 10^{4}$ & $1.0 \times 10^{7}$ \\
\hline \multirow{6}{*}{ Toy } & DBP & $2^{1}$ & $5.0 \times 10^{-1}$ & $5.0 \times 10^{-3}$ & $4.4 \times 10^{-1}$ & $1.1 \times 10^{-3}$ & $9.4 \times 10^{-1}$ & $6.0 \times 10^{-3}$ & $2.1 \times 10^{0}$ & $3.3 \times 10^{2}$ \\
\hline & DEHA & $170^{2}$ & $5.0 \times 10^{-3}$ & $5.0 \times 10^{-3}$ & $2.8 \times 10^{-5}$ & $6.9 \times 10^{-6}$ & $5.0 \times 10^{-3}$ & $5.0 \times 10^{-3}$ & $3.4 \times 10^{4}$ & $3.4 \times 10^{4}$ \\
\hline & DEHP & $3^{3}$ & $5.0 \times 10^{-1}$ & $5.0 \times 10^{-3}$ & $2.4 \times 10^{-2}$ & $8.6 \times 10^{-6}$ & $5.2 \times 10^{-1}$ & $5.0 \times 10^{-3}$ & $5.8 \times 10^{0}$ & $6.1 \times 10^{2}$ \\
\hline & DEP & $750^{4}$ & $5.0 \times 10^{-3}$ & $5.0 \times 10^{-3}$ & $8.7 \times 10^{-2}$ & $1.9 \times 10^{-3}$ & $9.2 \times 10^{-2}$ & $6.8 \times 10^{-3}$ & $8.2 \times 10^{3}$ & $1.1 \times 10^{5}$ \\
\hline & DIBP & $125^{5}$ & $5.0 \times 10^{-1}$ & $5.0 \times 10^{-3}$ & $3.3 \times 10^{-2}$ & $2.5 \times 10^{-5}$ & $5.3 \times 10^{-1}$ & $5.0 \times 10^{-3}$ & $2.4 \times 10^{2}$ & $2.5 \times 10^{4}$ \\
\hline & DINP & $15^{6}$ & $5.0 \times 10^{-1}$ & $5.0 \times 10^{-3}$ & $2.3 \times 10^{-4}$ & $1.5 \times 10^{-6}$ & $5.0 \times 10^{-1}$ & $5.0 \times 10^{-3}$ & $3.0 \times 10^{1}$ & $3.0 \times 10^{3}$ \\
\hline
\end{tabular}

${ }_{1}^{1}$ LOAEL, endpoint: germ cell development, species: rat [28], ${ }^{2}$ NOAEL, endpoint: changes in bodyweight and liver weight, species: rat [29], ${ }^{3}$ NOAEL, endpoint: nipple retention, species: rat [30], ${ }^{4}$ NOAEL, endpoint: decreased growth rate, species: rat [31] ${ }^{5}$ NOAEL, endpoint: nipple retention, species: rat [32], ${ }^{6}$ NOAEL, endpoint: hepatotoxicity, species: rat [33], DBP: dibutyl phthalate; DEHA: di(e-ethylhexyl)adipate); DEHP: di(2-ethylhexyl)phthalate); DEP: diethyl phthalate; DIBP: di-isobutyl phthalate; DINP: diisononyl phthalate. 
Table 4 presents the exposure ranges estimated by the probabilistic approach and its corresponding MOE values. Exposure through ingestion is estimated to be the highest in DEHP at $0.416 \mathrm{mg} \mathrm{kg}^{-1} \mathrm{~d}^{-1}$. The estimated exposure through ingestion in the same age group differs by chemicals within two orders of magnitude difference. The higher exposure in the younger age group to all plasticizers through ingestion is attributed to the higher frequency in mouthing behavior. For the dermal route, the exposure to DBP is the highest, $0.157 \mathrm{mg} \mathrm{kg}^{-1} \mathrm{~d}^{-1}$ (95th percentile in 3-12 years group), followed by DEHP and DEP. Unlike ingestion, differences between age groups were not as significant through dermal contacts. As exposure by ingestion is estimated to be 10 to 1000 times greater than by dermal contact, ingestion of the products determined the total exposure. Based on the total estimated exposure, the 95th percentile MOE values in all age groups were less than $100[34,35]$ in DBP and DEBP. The MOE value was the highest in DEP for the younger age group with 49,000 (95th percentile in 0-2 years group), followed by DEHA and DIBP. 
Table 4. Estimated exposure ranges via ingestion and dermal contact of chemicals in children's products and their corresponding margin of exposure (MOE) from reference doses

\begin{tabular}{|c|c|c|c|c|c|c|c|c|c|}
\hline \multirow{3}{*}{ Chemical } & \multirow{3}{*}{ Age Group } & \multicolumn{6}{|c|}{ Exposure Range $\left(\mathrm{mg} \mathrm{kg}^{-1} \mathrm{~d}^{-1}\right)$} & \multirow{2}{*}{\multicolumn{2}{|c|}{ MOE }} \\
\hline & & \multicolumn{2}{|c|}{ Ingestion } & \multicolumn{2}{|c|}{ Dermal } & \multicolumn{2}{|c|}{ Total } & & \\
\hline & & Median & $95 \%$ & Median & $95 \%$ & Median & $95 \%$ & Median & $95 \%$ \\
\hline \multirow[b]{2}{*}{ DBP } & $0-2$ years & $1.5 \times 10^{-2}$ & $9.6 \times 10^{-2}$ & $8.2 \times 10^{-3}$ & $1.2 \times 10^{-1}$ & $3.2 \times 10^{-2}$ & $1.9 \times 10^{-1}$ & $6.2 \times 10^{1}$ & $1.1 \times 10^{1}$ \\
\hline & $3-12$ years & $2.2 \times 10^{-3}$ & $1.5 \times 10^{-2}$ & $8.9 \times 10^{-3}$ & $1.6 \times 10^{-1}$ & $1.4 \times 10^{-2}$ & $1.7 \times 10^{-1}$ & $1.5 \times 10^{2}$ & $1.2 \times 10^{1}$ \\
\hline \multirow{2}{*}{ DEHA } & $0-2$ years & $1.6 \times 10^{-2}$ & $9.1 \times 10^{-2}$ & $1.9 \times 10^{-6}$ & $1.8 \times 10^{-5}$ & $1.6 \times 10^{-2}$ & $9.1 \times 10^{-2}$ & $1.1 \times 10^{4}$ & $1.9 \times 10^{3}$ \\
\hline & $3-12$ years & $2.3 \times 10^{-3}$ & $1.5 \times 10^{-2}$ & $9.1 \times 10^{-7}$ & $9.8 \times 10^{-6}$ & $2.3 \times 10^{-3}$ & $1.5 \times 10^{-2}$ & $7.5 \times 10^{4}$ & $1.2 \times 10^{4}$ \\
\hline \multirow{2}{*}{ DEHP } & $0-2$ years & $2.0 \times 10^{-2}$ & $4.2 \times 10^{-1}$ & $3.0 \times 10^{-4}$ & $3.0 \times 10^{-3}$ & $2.1 \times 10^{-2}$ & $4.2 \times 10^{-1}$ & $1.4 \times 10^{2}$ & $7.2 \times 10^{0}$ \\
\hline & $3-12$ years & $3.8 \times 10^{-3}$ & $7.2 \times 10^{-2}$ & $2.2 \times 10^{-4}$ & $2.9 \times 10^{-3}$ & $4.7 \times 10^{-3}$ & $7.5 \times 10^{-2}$ & $6.4 \times 10^{2}$ & $4.0 \times 10^{1}$ \\
\hline \multirow{2}{*}{ DEP } & $0-2$ years & $1.6 \times 10^{-2}$ & $9.1 \times 10^{-2}$ & $5.6 \times 10^{-4}$ & $1.3 \times 10^{-3}$ & $1.6 \times 10^{-2}$ & $9.2 \times 10^{-2}$ & $2.9 \times 10^{5}$ & $4.9 \times 10^{4}$ \\
\hline & 3-12 years & $2.3 \times 10^{-3}$ & $1.5 \times 10^{-2}$ & $2.6 \times 10^{-4}$ & $1.0 \times 10^{-3}$ & $2.6 \times 10^{-3}$ & $1.5 \times 10^{-2}$ & $4.8 \times 10^{4}$ & $7.4 \times 10^{3}$ \\
\hline \multirow{2}{*}{ DIBP } & $0-2$ years & $1.5 \times 10^{-2}$ & $1.0 \times 10^{-1}$ & $9.4 \times 10^{-6}$ & $8.1 \times 10^{-5}$ & $1.6 \times 10^{-2}$ & $1.0 \times 10^{-1}$ & $8.1 \times 10^{3}$ & $1.2 \times 10^{3}$ \\
\hline & 3-12 years & $2.3 \times 10^{-3}$ & $1.5 \times 10^{-2}$ & $3.7 \times 10^{-6}$ & $1.9 \times 10^{-5}$ & $2.3 \times 10^{-3}$ & $1.5 \times 10^{-2}$ & $5.5 \times 10^{4}$ & $8.3 \times 10^{3}$ \\
\hline \multirow{2}{*}{ DINP } & $0-2$ years & $1.7 \times 10^{-2}$ & $3.8 \times 10^{-1}$ & $3.1 \times 10^{-6}$ & $4.4 \times 10^{-5}$ & $1.7 \times 10^{-2}$ & $3.8 \times 10^{-1}$ & $8.8 \times 10^{2}$ & $3.9 \times 10^{1}$ \\
\hline & $3-12$ years & $2.6 \times 10^{-3}$ & $6.7 \times 10^{-2}$ & $2.1 \times 10^{-6}$ & $3.3 \times 10^{-5}$ & $2.6 \times 10^{-3}$ & $6.7 \times 10^{-2}$ & $5.8 \times 10^{3}$ & $2.2 \times 10^{2}$ \\
\hline
\end{tabular}

DBP: dibutyl phthalate; DEHA: di(e-ethylhexyl)adipate); DEHP: di(2-ethylhexyl)phthalate); DEP: diethyl phthalate; DIBP: di-isobutyl phthalate; DINP: diisononyl phthalate 


\section{Discussion}

The level of phthalate plasticizers in children's products was similar to those reported in other studies conducted in recent decades [12-18]. The optimal amount of phthalate plasticizers to be added in PVC and other plastics is likely to depend on the purpose of their addition, unless they are unintentionally added during production processes. There were no noticeable temporal trends in the patterns of plasticizer use in all analyzed products purchased within three years. Nevertheless, DEHP and DINP are the two most predominant phthalate plasticizers. The concentration of DEHP is the highest in most products in all categories. DBP and DEP were found steadily in children's products, although the detection frequency is low and the amount in products was minor. DIBP was detected in several products in the toy category with relatively high concentrations. Recently, DEHA has started appearing in products, as it is an alternative to DEHP [36,37].

The estimated MOE values in this study are relatively low, although the exposure was calculated by the single product category or chemical. Estimated total exposure using deterministic and probabilistic ways in this study is slightly greater than those in previous literature [38-42]. Lioy et al. reported the estimated daily phthalate intake from children's products and comparing with urine monitoring from several studies [40]. In the case of children, exposure through diet was the dominant pathway explaining more than $40 \%$ of total exposure to DEHP, followed by the use of childcare products $(>20 \%)$ and toys $(>10 \%)$. Kim et al. analyzed phthalate metabolites in the urine of elementary school children of Korea [41]. The converted daily exposure to DEHP was comparable with the result of DEHP in 3-12 years old age group in this study. Those bio-monitored exposure ranges are similar to the results of this study. As the daily intake estimated in the previous literature [40-42] includes all possible exposure routes including foods and dust, the exposure estimation in this study could be greater than those by the reverse-dosimetric estimation from biomonitoring. Dermal exposure estimated in this study shows similar ranges with the total exposure from those references, suggesting that the estimated level is rather high, because the daily intakes from the literature include both dietary and non-dietary routes.

The estimated exposure by a mathematical model is higher than that by human biomonitoring owing to the setting of exposure parameters preventing underestimation [22,35,39]. Likewise, the exposure algorithms adopted from CEM might exaggerate the exposure to plasticizers in children's products. The calculation of daily dose from ingestion requires the migration rate in the digestive tracts. The migration rate can be affected by many variables such as temperature, surrounding matrix, and migration time $[43,44]$. In CEM, however, the migration rate values are assigned to four discrete values, $10,0.1,1 \times 10^{-3}$, and $1 \times 10^{-4} \mathrm{mg} \mathrm{cm}^{-2} \mathrm{~h}^{-1}$, based on the concentration in products. Because the concentration of plasticizers in products was often very close to $1 \%(10,000 \mathrm{ppm})$, a huge deviation (100-fold) in the migration rate resulted from slight differences in plasticizer contents. Moreover, the suggested migration rates in CEM could be much higher than that measured in our study using in vivo and in vitro systems [33]. Various analytic methods (e.g., chewing or sucking as in vivo methods and shaking, tumbling, or ultrasonication as in vitro methods) were used to measure the migration rate. The reported migration rates of DINP ranged from $1.0 \times 10^{-4}$ to $8.3 \times 10^{-2} \mathrm{mg} \mathrm{cm}^{-2} \mathrm{~h}^{-1}$ for children's products [33]. Furthermore, all concentrations of DINP in reported products were higher than $1 \%$; thus, the suggested migration rate would be $10 \mathrm{mg} \mathrm{cm}^{-2} \mathrm{~h}^{-1}$ according to the CEM's exposure algorithm. Three to five orders of magnitude greater values of the migration rate than experimental values lead to the very low MOEs in this screening-level risk assessment based on the content of plasticizers. For a refined assessment, there is a need to obtain a reasonable migration rate using experimental determination or by a refined model.

In the case of daily dose from dermal absorption, the estimated exposure strongly depends on $F A$, although dermal exposure did not contribute to the overall exposure in this study. Low FA for DEHA, DEHP, and DINP owing to low water solubility resulted in lower dermal exposure [45]. Estimation of $F A$ based on water solubility could be an important source of uncertainty, because there are significant uncertainties in water solubility of sparingly soluble chemicals. In addition, $F A$ also depends on 
the chemical's solubility in skin surface lipids [44]. The migrated chemicals from products could be absorbed through skin surface matrices consisting of water and lipid; the dominant pathway depends on their affinity with water or lipid.

\section{Conclusions}

In this study, the concentrations of six plasticizers were analyzed in 3345 children's products purchased from 2017 to 2019 in Korea. Among them, 387 products contained at least one plasticizer over the detection limit, indicating that the use of phthalate plasticizers remains common in children's products. DEHP and DINP were frequently found in all categories. There is no significant temporal trend of phthalate use, due to the relatively short sampling duration.

The exposure to phthalate plasticizers via oral ingestion and dermal absorption and the corresponding MOEs were estimated by deterministic and probabilistic estimation. Overall, our results were relatively higher than those in the literature. Possible overestimation by exposure models is likely due to uncertainties in key parameters. The migration rate should be refined more precisely in the oral ingestion pathway, and the absorbed fraction, $F A$, should be a key parameter for estimating dermal exposure.

Author Contributions: Conceptualization, S.-H.C. and J.-H.K.; data curation, D.Y.K., Y.J. and J.-W.A.; formal analysis, D.Y.K.; funding acquisition, J.-H.K.; investigation, D.Y.K., Y.J., D.F.M.S.M., H.-S.K., D.-Y.K. and H.-W.K.; methodology, D.Y.K., Y.J. and S.-Y.P.; project administration, D.Y.K., S.-H.C. and J.-H.K.; resources, J.-H.K.; software, D.Y.K. and D.F.M.S.M.; supervision, S.-H.C.; validation, D.Y.K., Y.J. and D.F.M.S.M.; visualization, D.Y.K.; writing—original draft, D.Y.K. and Y.J.; writing—review and editing, D.Y.K., Y.J. and J.-H.K. All authors have read and agreed to the published version of the manuscript.

Funding: This work was supported by Korea Environment Industry and Technology Institute (KEITI) through "Technology Development Project for Safety Management of Household Chemical Products", funded by the Korea Ministry of Environment (MOE) (No. 2020002970001, No. 1485017105).

Conflicts of Interest: The authors declare no conflict of interest.

\section{References}

1. Takehisa, H.; Naoko, E.; Masahiko, S.; Katsuhide, T.; Moriuoki, O.; Keizoh, S.; Mutsuko, T.; Kenji, K.; Shin'ichiro, N.; Toshio, O. Release behavior of diethylhexyl phthalate from the polyvinyl-chloride tubing used for intravenous administration and the plasticized PVC membrane. Int. J. Pharm. 2005, 297, 30-37. [CrossRef] [PubMed]

2. Jeon, S.; Kim, K.-T.; Choi, K. Migration of DEHP and DINP into dust from PVC flooring products at different surface temperature. Sci. Total Environ. 2016, 547, 441-446. [CrossRef] [PubMed]

3. Gao, D.; Li, Z.; Wang, H.; Liang, H. An overview of phthalate acid ester pollution in China over the last decade: Environmental occurrence and human exposure. Sci. Total Environ. 2018, 645, 1400-1409. [CrossRef] [PubMed]

4. Matsumoto, M.; Hirata-Koizumi, M.; Ema, M. Potential adverse effects of phthalic acid esters on human health: A review of recent studies on reproduction. Regul. Toxicol. Pharm. 2008, 50, 37-49. [CrossRef]

5. Kamrin, M.A. Phthalate risks, phthalate regulation, and public health: A review. J. Toxicol. Environ. Health $B$ 2009, 12, 157-174. [CrossRef]

6. The European Commission. Commission regulation (EU) 2018/2005. Off. J. Eur. Union 2018, 61, 14-19.

7. U.S. Environmental Protection Agency (EPA). Available online: https://www.epa.gov/assessing-andmanaging-chemicals-under-tsca/phthalates (accessed on 18 November 2020).

8. U.S. Food and Drug Administration. Available online: https://www.fda.gov/regulatory-information/searchfda-guidance-documents/limiting-use-certain-phthalates-excipients-cder-regulated-products (accessed on 18 November 2020).

9. Ministry of Trade, Industry and Energy of Republic of Korea. Available online: http://motie.go.kr/TPTXZ/ motie/ms/nt/gosi/bbs/bbsView.do?bbs_seq_n=63555\&bbs_cd_n=5 (accessed on 18 November 2020).

10. Kawakami, T.; Isama, K.; Jinno, H. Skin transferability of phthalic acid ester plasticizers and other plasticizers using model polyvinyl chloride sheets. J. Environ. Sci. Health A 2020, 55, 1163-1172. [CrossRef] 
11. Oteef, M.D.Y.; Elhassan, M.S. Plastic toys and child care articles as a source of children exposure to phthalates and other plasticisers in Saudi Arabia. Int. J. Environ. Anal. Chem. 2020, 1-15. [CrossRef]

12. Stringer, R.; Labunska, I.; Johnston, P.; Siddorn, J.; Stephenson, A. Concentrations of phthalate esters and identification of other additives in PVC children's toys. Environ. Sci. Pollut. Res. 2000, 7, 27-36. [CrossRef]

13. Bouma, K.; Schakel, D.J. Migration of phthalates from PVC toys into saliva simulant by dynamic extraction. Food Addit. Contam. 2002, 19, 602-610. [CrossRef]

14. Ting, K.-C.; Gill, M.; Garbin, O. GC/MS screening method for phthalate esters in children's toys. J. AOAC Int. 2009, 92, 951-958. [CrossRef] [PubMed]

15. Gill, U.S.; Lalonde, P.J.; Chantal, P.D.; Subramanian, K.S. Analysis of diisononyl phthalate in PVC consumer products used by children. Int. J. Inj. Control Saf. 1999, 6, 223-234. [CrossRef]

16. Xie, M.; Wu, Y.; Little, J.C.; Marr, L.C. Phthalates and alternative plasticizers and potential for contact exposure from children's backpacks and toys. J. Expo. Sci. Environ. Epidemiol. 2016, 26, 119-124. [CrossRef] [PubMed]

17. Negev, M.; Berman, T.; Reicher, S.; Sadeh, M.; Ardi, R.; Shammai, Y. Concentrations of trace metals, phthalates, bisphenol A and flame-retardants in toys and other children's products in Israel. Chemosphere 2018, 192, 217-224. [CrossRef] [PubMed]

18. Babich, M.A.; Bevington, C.; Dreyfus, M.A. Plasticizer migration from children's toys, child care articles, art materials, and school supplies. Regul. Toxicol. Pharm. 2020, 111, 104574. [CrossRef]

19. Xu, Y.; Cohen Hubal, E.A.; Clausen, P.A.; Little, J.C. Predicting residential exposure to phthalate plasticizer emitted from vinyl flooring: A mechanistic analysis. Environ. Sci. Technol. 2009, 43, 2374-2380. [CrossRef]

20. U.S. Consumer Product Safety Commission. Available online: https://www.cpsc.gov/s3fs-public/ CPSC-CH-C1001-09.4_Standard_Operating_Procedure_for_Determination_of_phthalates.pdf? Uax14IIPOM6FkTpgas9fFKWLRsOCue0t (accessed on 18 November 2020).

21. National Institute of Environmental Research of Republic of Korea. Available online: https: //www.nier.go.kr/NIER/cop/bbs/selectNoLoginBoardArticle.do?menuNo=13001\&bbsId=BBSMSTR_ 000000000031\&nttId=27366\&Command=READ (accessed on 18 November 2020).

22. Giovanoulis, G.; Bui, T.; Xu, F.; Papadopoulou, E.; Padilla-Sanchez, J.A.; Covaci, A.; Haug, L.S.; Cousins, A.P.; Magnér, J.; Cousins, I.T.; et al. Multi-pathway human exposure assessment of phthalate esters and DINCH. Environ. Int. 2018, 112, 115-126. [CrossRef]

23. U.S. Environmental Protection Agency (EPA). Available online: https://www.epa.gov/tsca-screening-tools/ consumer-exposure-model-cem-version-21-users-guide (accessed on 18 November 2020).

24. Thompson, K.M.; Burmaster, D.E.; Crouch, E.A.C. Monte Carlo techniques for quantitative uncertainty analysis in public health resk assessments. Risk Anal. 1992, 12, 53-63. [CrossRef]

25. U.S. Environmental Protection Agency (EPA). Available online: https://www.epa.gov/risk/risk-assessmentguidance-superfund-rags-volume-iii-part (accessed on 18 November 2020).

26. National Institute of Environmental Research of Republic of Korea. Available online: https://ecolibrary.me. go.kr/nier/\#/search/detail/5609057 (accessed on 18 November 2020).

27. U.S. Environmental Protection Agency (EPA). Available online: https://cfpub.epa.gov/ncea/risk/recordisplay. cfm?deid=199243 (accessed on 18 November 2020).

28. Lee, K.Y.; Shibutani, M.; Takagi, H.; Kato, N.; Takigami, S.; Uneyama, C.; Hirose, M. Diverse developmental toxicity of di-n-butyl phthalate in both sexes of rat offspring after maternal exposure during the period from late gestation through lactation. Toxicology 2004, 203, 221-238. [CrossRef]

29. U.S. Environmental Protection Agency (EPA). Available online: https://cfpub.epa.gov/ncea/iris2/ chemicalLanding.cfm?substance_nmbr=420 (accessed on 18 November 2020).

30. Christiansen, S.; Scholze, M.; Dalgaard, M.; Vinggaard, A.M.; Axelstad, M.; Kortenkamp, A.; Hass, U. Synergistic disruption of external male sex organ development by a mixture of four antiandrogens. Environ. Health Persp. 2009, 117, 1839-1846. [CrossRef]

31. Brown, D.; Butterworth, K.R.; Gaunt, I.F.; Grasso, P.; Gangolli, S.D. Short-term oral toxicity study of diethyl phthalate in the rat. Food Cosmet. Toxicol. 1978, 16, 415-422. [CrossRef]

32. Saillenfait, A.M.; Sabaté, J.-P.; Gallissot, F. Diisobutyl phthalate impairs the androgen-dependent reproductive development of the male rat. Reprod. Toxicol. 2008, 26, 107-115. [CrossRef] [PubMed] 
33. European Chemicals Agency (ECHA). Evaluation of New Scientific Evidence Concerning DINP and DIDP in Relation to Entry 52 of Annex XVII to REACH Regulation (EC) No 1907/2006. 2013. Available online: https://echa.europa.eu/documents/10162/31b4067e-de40-4044-93e8-9c9ff1960715 (accessed on 18 November 2020).

34. Renwick, A.G. Data-derived safety factors for the evaluation of food additives and environmental contaminants. Food. Addit. Contam. 1993, 10, 275-305. [CrossRef] [PubMed]

35. Arnold, S.M.; Greggs, B.; Goyak, K.O.; Landenberger, B.D.; Mason, A.M.; Howard, B.; Zaleski, R.T. A quantitative screening-level approach to incorporate chemical exposure and risk into alternative assessment evaluations. Integr. Environ. Assess. Manag. 2017, 13, 1007-1022. [CrossRef]

36. Van Vliet, E.D.S.; Reitano, E.M.; Chhabra, J.S.; Bergen, G.P.; Whyatt, R.M. A review of alternatives to di (2-ethylhexyl) phthalate-containing medical devices in the neonatal intensive care unit. J. Perinatol. 2011, 31, 551-560. [CrossRef]

37. Nehring, A.; Bury, D.; Ringbeck, B.; Kling, H.-W.; Otter, R.; Weiss, T.; Brüning, T.; Koch, H.M. Metabolism and urinary excretion kinetics of di(2-ethylhexyl) adipate (DEHA) in four human volunteers after a single oral dose. Toxicol. Lett. 2020, 321, 95-102. [CrossRef]

38. Chang, J.-W.; Lee, C.-C.; Pan, W.-H.; Chou, W.-C.; Huang, H.-B.; Chiang, H.-C.; Huang, P.-C. Estimated Daily Intake and Cumulative Risk Assessment of Phthalates in the General Taiwanese after the 2011 DEHP Food Scandal. Sci. Rep. 2017, 7, 45009. [CrossRef]

39. Wang, Y.; Zhu, H.; Kannan, K. A Review of Biomonitoring of Phthalate Exposures. Toxics 2019, 7, 21. [CrossRef]

40. Lioy, P.J.; Hauser, R.; Gennings, C.; Koch, H.M.; Mirkes, P.E.; Schwetz, B.A.; Kortenkamp, A. Assessment of phthalates/phthalate alternatives in children's toys and childcare articles: Review of the report including conclusions and recommendation of the Chronic Hazard Advisory Panel of the Consumer Product Safety Commission. J. Expo. Sci. Environ. Epid. 2015, 25, 343-353. [CrossRef]

41. Kim., S.; Kang, S.; Lee, G.; Lee, S.; Jo, A.; Kwak, K.; Kim, D.; Koh, D.; Kho, Y.L.; Kim, S.; et al. Urinary phthalate metabolites among elementary school children of Korea: Sources, risks, and their associaton with oxidative stress marker. Sci. Total Environ. 2014, 472, 49-55. [CrossRef]

42. Guo, Y.; Alomirah, H.; Cho, H.-S.; Minh, T.B.; Mohd, M.A.; Nakata, H.; Kannan, K. Occurrence of phthalate metabolites in human urine from several asian countries. Environ. Sci. Technol. 2011, 45, 3138-3144. [CrossRef] [PubMed]

43. Gong, M.; Zhang, Y.; Weschler, C.J. Predicting dermal absorption of gas-phase chemicals: Transient model development, evaluation, and application. Indoor Air 2014, 24, 292-306. [CrossRef] [PubMed]

44. Zeng, D.; Kang, Y.; Chen, J.; Li, A.; Chen, W.; Li, Z.; He, L.; Zhang, Q.; Luo, J.; Zeng, L. Dermal bioaccessibility of plasticizers in indoor dust and clothing. Sci. Total Environ. 2019, 672, 798-805. [CrossRef] [PubMed]

45. Letinski, D.J.; Connelly, M.J., Jr.; Peterson, D.R.; Parkerton, T.F. Slow-stir water solubility measurements of selected alcohols and diesters. Chemosphere 2002, 48, 257-265. [CrossRef]

Publisher's Note: MDPI stays neutral with regard to jurisdictional claims in published maps and institutional affiliations.

(C) 2020 by the authors. Licensee MDPI, Basel, Switzerland. This article is an open access article distributed under the terms and conditions of the Creative Commons Attribution (CC BY) license (http://creativecommons.org/licenses/by/4.0/). 